\title{
Kahoot! As a Formative Assessment Tool in Foreign Language Learning: A Case Study in Greek as an L2
}

\author{
Georgios D. Kapsalis \\ Department of Primary Education, University of Ioannina, Ioannina, Greece \\ Alexandra Galani \\ Department of Primary Education, University of Ioannina, Ioannina, Greece \\ Olga Tzafea \\ Department of Philosophy, University of Ioannina, Ioannina, Greece
}

\begin{abstract}
Our study investigates the effectiveness of Kahoot! as a formative assessment tool in the consolidation of grammatical phenomena in adult foreign language learning. Kahoot! was used in a multilingual and multicultural learning environment, where A1-level Greek was the target language. An experimental quantitative methodology was employed to compare progress made by students using Kahoot! (experimental group) compared to those using traditional methods such as paper and pencil tests (control group). Pre-tests and post-tests were administered to both groups to check if students had better assimilated the grammatical phenomena they had been taught. The study was carried out in the Center for the Study of the Hellenic Language and Culture at the University of Ioannina (Greece). Overall findings reveal that both groups performance in the post-tests showed a statistically significant improvement, however there was not a statistically significant difference between the performance of the two groups.
\end{abstract}

Index Terms - Kahoot!, Greek as a foreign/second language, formative assessment

\section{INTRODUCTION}

The rapid development of new technologies has brought to the fore the integration of gamification in education (e.g. Hwang \& Wu, 2012). According to Deterding, Dixon, Khaled and Nacke (2011), "gamification is the use of game design elements in non-game contexts" (p. 10). Several gamified applications have been designed, such as Audioboom, Brainscape, ClassDojo, Class Realm, Clickers, Course Hero, Duolingo, Edmodo, Kahoot!, Poll Everywhere, Quizlet, Quizizz, Socrative, Veri, Zondle. These have been applied to various educational disciplines and levels (schools, colleges, Higher Education), in subjects as diverse as chemistry (Pretorius, 2016), medical education (Ismail \& Mohammad, 2017), and foreign language teaching and learning (Lam, 2014; Michos, 2017).

According to Wang (2015), there are three reasons to incorporate gamification in teaching. Firstly, it enables teachers to monitor student progress in real time (Sindre, Nattvig \& Jahre, 2009) and provide immediate feedback (Spodark, 2010). Secondly, it results in the advancement of student skills that could not have been otherwise developed if traditional teaching methods were followed (Owston, Wideman, Ronda \& Brown, 2009). Thirdly, it improves student learning, motivation and engagement. Consequently, gamification bridges traditional classroom-based teaching and learning with the digital world (Oomen-Early \& Early, 2015).

The present study aims to evaluate the effectiveness of gamification in adult foreign language learning. More specifically, we are interested in comparing the effectiveness of Kahoot! as a formative assessment tool versus traditional methods (i.e. paper-and-pencil tests), when monitoring student progress in the consolidation of grammatical phenomena. Kahoot! was used in an adult -multicultural and multilingual- foreign language teaching environment, the target language of which was A1-level Greek. We propose that Kahoot! may serve as a tool for formative assessment, necessarily alongside traditional methods.

The remainder of the paper is organised as follows: in section II.A we briefly outline gamification prior to providing a sketch of Kahoot! (II.B). Our experimental study and the statistical results are presented in section III, while the paper concludes in section IV.

\section{GAMIFICATION}

\section{A. Background Information}

Gamification has been widely discussed in the literature, as shown in Section I. In this section, we do not aim to offer 
an extensive literature review, but instead outline the benefits of gamification and briefly refer to studies which investigate the use of gamified tools in foreign language teaching and learning mainly in Higher Education.

Generally speaking, gamification contributes to the improvement of the learning environment that further enhances knowledge acquisition (Papastergiou, 2009). Learning outcomes and classroom dynamics are also positively affected (Rosas et al., 2003). It may also trigger changes in students' attitudes and behaviours as well as address the educational needs of different types of learners (Lee \& Hammer, 2011). Well-designed gamified tools may increase student learning achievements (Hwang, Sung, Hung \& Huang, 2013) and learning performance (Jang, Park \& Yi, 2015) as they allow students to review class content (Icard, 2014).

Moreover, students are attracted by the competitive nature of games, they learn to handle success and failure and they also learn how to use critical thinking and problem-solving skills (Icard, 2014). Students show a positive attitude towards the incorporation of gamification in the learning process (Galbis-Córdova, Marti-Parreño \& Currás Pérez, 2017) for several reasons; i.e. gamification is entertaining, it reduces stress during assessment (Barrio, Munoz-Organero \& Soriano, 2016), it increases student engagement and motivation (Dickey, 2011; Lee \& Hammer, 2011) as well as group communication and co-operation (Lekka, Sipsas \& Pagge, 2013). Teachers also feel positive about the incorporation of gamification in the learning process as it increases student productivity and creativity (Sanchez-Mena, Marti-Parreno \& Aldas-Manzano, 2016).

The vast majority of studies about gamification mainly explore students' perceptions on issues such as: a) Does gamification increase student motivation, participation and self-assessment? b) Does gamification add a fun element in the teaching process? c) Does gamification provide immediate feedback? d) Does gamification contribute to learning?

Other studies evaluate student performance in gamification. Gamification may result in students' scoring better in assessed work or exams (Barata, Gama, Jorge \& Gonçalves, 2013; Borrell, Cosmas, Grymes \& Radunzel, 2017; Jang, Park \& Yi, 2015) or it may result in no improvement (Long \& Aleven, 2014; Hanus \& Fox, 2015). The small number of participants or the short period of time over which some studies were implemented might have influenced the results.

Gamified tools have been incorporated in foreign language teaching and learning (i.e. Hasegawa, Koshinon \& Ban, 2015). Emphasis is often placed on vocabulary learning (Faisal, 2017; Medina \& Hurtado, 2017) or reading compliance (Rodríguez-Prieto, 2014) in languages such as English or Spanish in various educational settings (i.e. Primary Education, Colleges, Higher Education). Fewer studies investigate the role gamification plays in grammatical content learning (i.e. Michos, 2017). Once again, these studies primarily examine students' perceptions about the effectiveness of gamified applications on issues such as motivation (i.e. Liu \& Wang, 2017). Overall, they show that students believe that gamification contributes to language learning.

Generally speaking, quantitative research studies which address the question of whether gamification actually improves language learning do not seem to reach a unified conclusion. According to Faisal (2017), students do not benefit significantly from the application of mobile augmented reality in foreign language learning, despite the fact that their motivation is increased. Rodríguez-Prieto (2014) found that the use of Clickers in a Spanish foreign language class did not result in students' better performance as far as reading compliance is concerned. On the contrary, Medina and Hurtado (2017) conclude that students' mean scores in vocabulary learning activities were increased and, in line with the findings of Abrams and Walsh (2014), gamification also increased students' vocabulary knowledge.

\section{B. Kahoot!}

Kahoot! is a free game-based digital platform which has been developed by the Norwegian University of Science and Technology (https://kahoot.com/). It contains design features which entice learning activities (points, leaderboards, timelines, sound effects, nicknames). Teachers create quizzes, discussions, and/or surveys in a simple and straightforward guided way. Quizzes may include multiple-choice questions, pictures and videos. A time limit may be set (from 5 to 120 seconds) for each question. Once a quiz is created, teachers may randomise the order of the questions and they can choose to make their quiz public or private. Students may or may not earn points for each question they answer correctly, depending on the settings teachers apply. When a task is completed, a leaderboard of the top players is displayed. Students' scores may be saved in an excel file which allows teachers to monitor student progress. In class, all you need is a computer, a projector and internet access. Teachers log in their Kahoot! account in order to activate the quiz. Students use their personal devices (a web browser is required) and gain access to the quiz by inserting a pin for the game. They can use their real names or nicknames and can participate as individuals or as a group. Throughout the gaming process, sound effects may further create an exciting and playful atmosphere (see also Mu and Paparas (2015) for a description of how to use this tool and Boden and Hart (2018) for an overview of the tool's strengths and weaknesses).

Kahoot! has been incorporated in various educational disciplines, such as chemistry (Pretorius, 2016), computer programming (Fotaris, Mastoras, Leinfellner \& Rosunally, 2016), foreign language learning (i.e. Budiati, 2017; Dellos, 2015; Iaremenko, 2017; Medina \& Hurtado, 2015; Zarzycka-Piskorz, 2016), medicine (Ismail et al, 2019), psychology (Iwamoto, Hargis, Taitano \& Vuong, 2017).

Generally speaking, Kahoot! is a useful and pleasant tool. It is not a one-way teaching tool where teachers ask questions which need to be answered by individual students. All students are invited to respond to questions in real time and, simultaneously, they compete with each other. They also receive immediate feedback. Teachers may pause the quiz and discuss answers with the class. So, Kahoot! promotes active student learning as it focuses on student 
engagement, motivation, collaboration and knowledge sharing through a gaming experience (Dellos, 2015; Licorish, George, Owen \& Daniel, 2017). The interested reader is referred to Wang and Tahir (2020) for a review of studies on Kahoot!.

\section{THE STUDY}

In our study, we aim to investigate the effectiveness of Kahoot! as a formative assessment tool in adult foreign language learning. Towards this end, we compare students' performance in tests carried out in Kahoot! versus traditional methods (i.e. paper-and-pencil tests). We focus on the consolidation of grammatical phenomena at an A1level (based on the Common European Framework of Reference for Languages) in Greek, a morphologically rich language. Our research hypothesis is based on the view that students' performance in Kahoot! is equal to their performance when traditional assessment methods are applied, given the fact that Kahoot! is a tool which serves the purposes of formative assessment by definition.

\section{A. Methodology}

The tool's effectiveness was tested in a multilingual and multicultural learning environment at the Center for the Study of the Hellenic Language and Culture at the University of Ioannina in Greece during the academic years 2017 2019. The target language was A1-level Greek. The sample consisted of students who participated in language learning educational programmes. The same curriculum and teaching materials were adopted. Students had a similar educational background (Tertiary Education). Their first languages were different. They were also learning Greek for different reasons. The survey was carried out with the help of the two class teachers.

The assumptions and the conceptual and functional definitions of the research were first set. The data collection tools (pre- and post-tests) were constructed, taking into account the specifications, the type and number of questions, and the conditions. Sixty-six participants were chosen by random sampling and divided into two groups: a control group (traditional formative assessment - paper and pencil test) of thirty-four students and an experimental group (Kahoot!) of thirty-two students. Both groups participated in a pre-test and a post-test in order to examine the progress students made on the basis of the feedback they received following the completion of the pre-test. More specifically, during 2017-2018, both the control group and the experimental group consisted of seventeen students each. In 2018-2019, the control group consisted of seventeen students whereas the experimental of fifteen students. A total of forty-nine students were female and seventeen male; twenty-six females and eight males (2017-2018), twenty-three females and nine males (2018-2019). The tests were conducted in the same teaching weeks during both academic years and students were tested on the same grammatical phenomena and items previously taught in classes (i.e. present tense verbs, nouns in nominative and accusative (singular and plural)).

The control group completed the pre-test in class and received feedback in the next class, once the tests were marked by the teachers. In order to improve the teaching and learning process, teachers praised students' efforts and referred to common mistakes, revised the necessary materials and gave students the opportunity to ask further questions. As far as the experimental group is concerned, the majority of the participants had not used Kahoot! prior to the implementation of the study. Students in this group participated in a Kahoot!-test session to familiarise themselves with the gamification tool. Once this session was completed, the experimental group completed the pre-test. Once a question was completed, teachers paused the quiz and asked students to provide explanations in reference to the (in)correctness of their answers. Where necessary, further explanations were given by the teachers. In this way, students received immediate feedback and revised the teaching material. In the post-test, students did not receive any feedback from the teachers while they were completing the quiz.

\section{B. Results}

Collected data were analysed using an independent t-test with p-value as well as a paired sample t-test. The differences in means, standard deviations and standard error means between the control and the experimental group were examined. The overall results of the analysis are presented in Figure.1. 


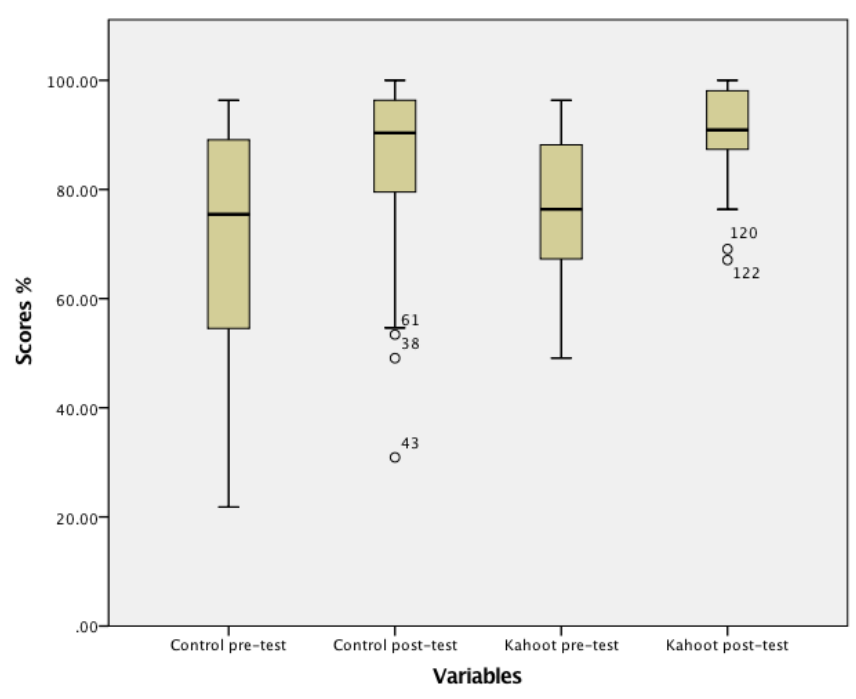

Figure 1. Group statistics visualisation

Firstly, we were interested in evaluating students' performance in the pre-test and the post-test in the control versus the experimental group. Levene's test was run to test the quality of variance between the two groups (Table.I).

In line with the results presented in Table.I and since the Sig. (2-tailed) is $>0.05$ both in the pre-test $(\mathrm{p}=.084)$ and the post-test $(\mathrm{p}=.079)$, we conclude that there is no statistically significant difference in the performance of the control versus the experimental group.

TABLE. I

INDEPENDENT T-TEST FOR BOTH GROUPS

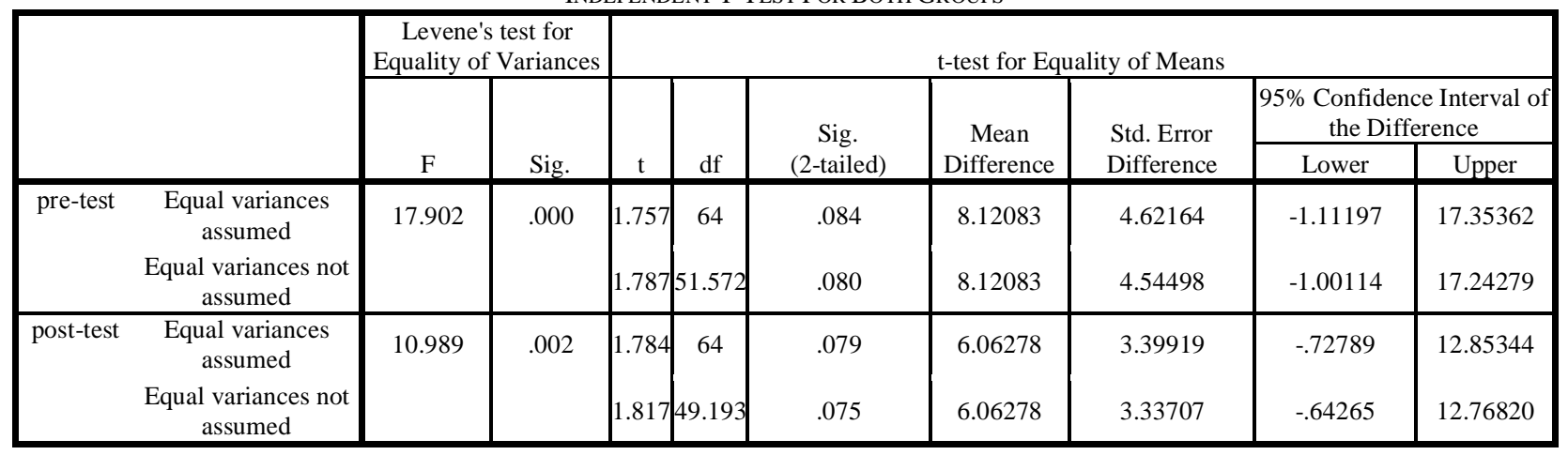

Next we ran a paired sample t-test in order to investigate students' progress in the pre-test and the post-test in the control and the experimental group, respectively. The results of the analysis are presented in Table.II.

\begin{tabular}{|ll|l|l|l|l|}
\hline \multicolumn{9}{|c|}{ TABLE. II } \\
PAIRED T-TEST & Std. Deviation & Std. Error Mean \\
\hline \multirow{2}{*}{ Pair 1 } & Mean & N & 23.11796 & 3.96470 \\
& Control_pre-test & 69.0382 & 34 & 17.29281 & 2.96569 \\
\cline { 2 - 6 } Pair 2 & Control_post-test & 84.1094 & 34 & 12.57043 & 2.22216 \\
& Experimental_pre-test & 77.1591 & 32 & 8.65463 & 1.52994 \\
& Experimental_post-test & 90.1722 & 32 & & \\
\hline
\end{tabular}

The mean score of the control group in the pre-test was $\mathrm{M}=69.0382(\mathrm{SD}=23.11796)$ while in the post test it was $\mathrm{M}=84.1094$ ( $\mathrm{SD}=17.29281)$. On the other hand, the mean score for the experimental group in the pre-test was $\mathrm{M}=77.1591$ ( $\mathrm{SD}=12.57043$ ) whereas in the post-test it was $\mathrm{M}=90.1722$ ( $\mathrm{SD}=8.65463)$. Students' performance in the post-tests improved, with a positive correlation in both groups, as shown in Table.III.

TABLE.III

PAIRED T-TEST - CORRELATIONS

\begin{tabular}{|lr|c|c|c|}
\hline & & $\mathrm{N}$ & Correlation & Sig. \\
\hline Pair 1 & Control_pre-test_post_test & 34 & .762 & .000 \\
\hline Pair 2 & Experimental_pre-test_post-test & 32 & .676 & .000 \\
\hline
\end{tabular}

Since the Sig.(2-tailed) is $<0.05(\mathrm{p}=.000)$ in both the control and the experimental group, as shown in Table.IV, there 
is a statistically significant difference in the students' performance in the pre-test and the post-test in both groups.

TABLE. IV

PAIRED T-TEST - DIFFERENCES

\begin{tabular}{|c|c|c|c|c|c|c|c|c|c|}
\hline & \multicolumn{5}{|c|}{ Paired Differences } & & \multirow[b]{3}{*}{ df } & \multirow{3}{*}{$\begin{array}{l}\text { Sig. } \\
\text { tailed) }\end{array}$} \\
\hline & & \multirow[b]{2}{*}{ Mean } & \multirow[b]{2}{*}{ Std. Deviation } & \multirow{2}{*}{$\begin{array}{l}\text { Std. } \\
\text { Mean }\end{array}$} & \multicolumn{2}{|c|}{$\begin{array}{l}95 \% \text { Confidence Interval of } \\
\text { the Difference }\end{array}$} & & & \\
\hline & & & & & Lower & Upper & t & & \\
\hline Pair 1 & $\begin{array}{l}\text { Control_pre-test } \\
\text { Control_post-test }\end{array}$ & -15.07118 & 14.97696 & 2.56853 & -20.29688 & -9.84547 & -5.868 & 33 & .000 \\
\hline Pair 2 & $\begin{array}{l}\text { Experimental__ pre-test } \\
\text { Experimental_post-test }\end{array}$ & -13.01313 & 9.26195 & 1.63730 & -16.35241 & -9.67384 & -7.948 & 31 & .000 \\
\hline
\end{tabular}

Consequently, it seems that both methods of formative assessment had a positive effect on the students' performance in the consolidation of grammatical phenomena in adult foreign language learning.

\section{DISCUSSION - CONCLUDING REMARKS}

Teaching and learning a foreign language is a rewarding and, at the same time, a demanding process during which teachers and learners are in constant interaction. Amongst other things, teachers have to create learning environments which address the educational needs of different types of learners. One of the ways that teachers achieve this is through the teaching materials and tools they use as well as their teaching methods. The increasing impetus of information and communication technology in classrooms further provides teachers with educational tools -e.g. gamification- that create an effective teaching and learning experience. As we have already seen in the previous sections, there are several benefits to using gamification. Gamification tools increase student knowledge, motivation and engagement. They also create an active commitment that supports problem solving skills in teaching environments and cultivates students' abilities to learn from their mistakes in a safe learning environment. The positive effects of gamification are often depicted in students' scores. Consequently, research studies should address the question of whether gamification can be used as tools to measure students' learning progress.

In our study, we investigated the effectiveness of Kahoot! as means of formative assessment in the consolidation of grammatical phenomena (at an A1-level) in adult foreign language learning. Our aim was to test whether Kahoot! is as effective as traditional assessment methods. Our working hypothesis, namely students' performance in Kahoot! is equal to their performance in paper-and-pencil tests, was confirmed. According to the analysis of the quantitative data, it was found that the students' performance in Kahoot! showed no statistically significant difference when compared to the students' performance in the paper-and-pencil tests. Simultaneously, students' performance in both groups increased in the post-tests. We can thus suggest that Kahoot! may serve as a method of formative assessment in the consolidation of grammatical phenomena in adult foreign language learning, alongside traditional ones (paper-and-pencil tests). The latter can be used to further test student performance on grammar through exercises which focus on students' writing skills. The effectiveness of Kahoot! as a suitable tool for formative assessment was also depicted in the study of Ismail et al. (2019).

Moreover, our findings -on the basis of students' performance in the Kahoot! pre- and the post-tests- are in line with previous reports in the literature as far as foreign language learning is concerned. Kahoot! increased students' performance in English (Wichadee \& Pattanapichet, 2018), in reading compliance (Rodríguez-Prieto, 2014) and in vocabulary knowledge (Ciaramella, 2017; Klimova \& Kacetl, 2018). Moreover, Iwamoto, Hargis, Taitano and Vuong (2017) found that Kahoot! had a positive impact on psychology students' academic performance. In the study of Şad and Özer (2019), it is reported that students who participated in a teacher education programme scored higher marks in assessment through Kahoot!

As it has been noted by Wang and Tahir (2020), "Kahoot! can have a positive effect on learning compared to other tools and approaches and for various contexts and domains. All studies that include statistical significance tests and effect sizes support this conclusion" (p. 9). Through Kahoot! students can revise newly acquired teaching material and can also receive rich and immediate feedback. Additionally, they feel positive about the use and the benefits of the gamification tool in class, as shown by Dellos (2015) who used Kahoot! in English learning classes. Fotaris, Mastoras, Leinfellner and Rosunally (2016) also found that students' engagement and learning experience are positively affected by the use of Kahoot!, when the tool was used in a university computer programming course. Similar conclusions were reached by Michos (2017), who used Kahoot! in a Spanish language course. He found that students believe that it increases motivation and is effective as a review activity for grammar and vocabulary. In addition, Zarzycka-Piskorz (2016) investigated university students' perceptions about English grammar learning through the gamified tool. In her study, students were positive about Kahoot!, as it made the learning process more effective and funny. The effectiveness of Kahoot! for the enhancement of language skills and students' classroom engagement when applied to a university English course was highlighted by Muhridza, Hazwani, Rosli, Sirri and Samad (2018). According to Tewthanom (2019), Kahoot! is an effective tool for improving pharmacy students' learning skills.

As we have already seen, students' performance in Kahoot! fits the general picture of the effectiveness of 
gamification in education; i.e. students achieved better scores in the studies of Barata, Gama, Jorge and Gonçalves (2013), Borrell, Cosmas, Grymes and Radunzel (2017) and Jang, Park and Yi (2015), and gamification resulted in the increase of vocabulary knowledge according to Abrams and Walsh (2014).

Prior to reaching our conclusion, we acknowledge the limitations of the study, i.e. the number of the tests that are to be carried out over an extended period (e.g. semester) or the involvement of more participants from diverse backgrounds. ${ }^{1} \mathrm{We}$, therefore, propose that the utilisation of Kahoot! in education, and more specifically in foreign language teaching and learning, can be only seen as a positive addition to the teaching and learning process. It goes without saying that by no means do we suggest that gamification tools should be solely used for student assessment. Rather we claim that traditional formative assessment methods can be enriched through the use of gamification tools, bearing in mind the positive effects of gamification in relation to student engagement, motivation, collaboration and knowledge sharing (Dellos, 2015; Licorish, George, Owen \& Daniel, 2017).

\section{ACKNOWLEDGMENTS}

We are grateful to Dr Beck Sinar for her insightful comments and for proofreading the manuscript.

\section{REFERENCES}

[1] Abrams, S. S. \& S. Walsh (2014). Gamified vocabulary: Online resources and enriched language learning. Journal of Adolescent and Adult Literacy 58.1, 49-58. Doi: 10.1002/jaal.315.

[2] Barata, G., S. Gama, J. Jorge \& D. Gonçalves (2013). Improving participation and learning with gamification. ACM International Conference Proceeding Series, 9-16. Doi: 10.1145/2583008.2583010.

[3] Barrio, C. M., M. Muñoz-Organero \& J. S. Soriano (2016). Can gamification improve the benefits of student response systems in learning? An experimental study. IEEE Transactions on Emerging Topics in Computing 4.3, 429-438.

[4] Boden, G. \& L. Hart (2018). Kahoot - Game Based Student Response System. Compass: Journal of Learning and Teaching 11.1. Doi: 10.21100/compass.v11i1.668.

[5] Borrell, J., N. Cosmas, J. Grymes \& J. Radunzel. (2017). The Effectiveness of Kahoot! As a Pre-Lesson Assessment Tool. The U.S Military Academy at West Point.

[6] Budiati, B. (2017). ICT (Information and communication technology) use: Kahoot program for English students' learning booster. The $1^{\text {st }}$ Education and Language International Conference Proceedings. Center for International Language Development of Unissula. pp. 178-188.

[7] Ciaramella, K. E. (2017). The effects of Kahoot! on vocabulary acquisition and retention of students with learning disabilities and other health impairments. Rowan University. Master Thesis.

[8] Dellos, R. (2015). Kahoot! A digital game resource for learning. International Journal of Instructional Technology and Distance Learning 12, 49-52.

[9] Deterding, S., D. Dixon, R. Khaled \& L. Nacke (2011). From game design elements to gamefulness: Defining gamification. Proceedings of the $15^{\text {th }}$ International Academic MindTrek Conference: Envisioning Future Media Environments, MindTrek 2011 11, 9-15. Doi: 10.1145/2181037.2181040.

[10] Dickey, M. (2011). World of Warcraft and the impact of game culture and play in an undergraduate game design course. Computers \& Education 56, 200-209. Doi: 10.1016/j.compedu.2010.08.005.

[11] Faisal, S. (2017). Gamification of foreign language vocabulary learning using mobile augmented reality. IEEE. Doi: 10.13140/RG.2.2.34941.41442.

[12] Fotaris, P., T. Mastoras, R. Leinfellner \& Y. Rosunally (2016). Climbing up the leaderboard: An empirical study of applying gamification techniques to a computer programming class. The Electronic Journal of E-Learning 14.2, 94-110.

[13] Galbis-Córdova, A., J. Marti-Parreño \& R. Currás Pérez (2017). Higher education students' attitude towards the use of gamification for competencies development. Journal of E-Learning and Knowledge Society 13, 129-146. Doi: 10.20368/1971$8829 / 1279$.

[14] Hanus, M. D., \& J. Fox (2015). Assessing the effects of gamification in the classroom: A longitudinal study on intrinsic motivation, social comparison, satisfaction, effort, and academic performance. Computers \& Education 80, $152-161$.

[15] Hasegawa, T., M. Koshino, \& H. Ban (2015). An English vocabulary learning support system for the learner's sustainable motivation. SpringerPlus 4, 99. Doi: 10.1186/s40064-015-0792-2.

[16] Hwang, G. J., H. Y. Sung, C. M. Hung \& I. Huang. (2013). A learning style perspective to investigate the necessity of developing adaptive learning systems. Educational Technology \& Society 16.2, 188-197.

[17] Hwang, G. J. \& P. H. Wu (2012). Advancements and trends in digital game-based learning research: A review of publications in selected journals from 2001 to 2010. British Journal of Educational Technology 43. Doi: 10.1111/j.1467-8535.2011.01242.x.

[18] Iaremenko, N. V. (2017). Enhancing English language learners' motivation through online games. Information Technologies and Learning Tools 59.3, 126-133.

[19] Iwamoto, H. D., J. Hargis, E. J. Taitano \& K. Vuong (2017). Analyzing the efficacy of the testing effect using Kahoot ${ }^{\mathrm{TM}}$ on student performance. Turkish Online Journal of Distance Education 18.2, 80-93.

[20] Icard, S. B. (2014). Educational technology best practices. International Journal of Instructional Technology and Distance Learning 11.3, 37-41.

[21] Ismail, M. A. A, A. Ahmad, J. A. M. Mohammad, N. M. R. M. Fakri, M. Z. M. Nor \& M. N. M. Pa (2019). Using Kahoot! as a formative assessment tool in medical education: a phenomenological study. BMC Medical Education 19: 230. Doi:

\footnotetext{
${ }^{1}$ The reason for which any greater positive effects in the experimental group's performance were not observed, given the benefits of gamification as exemplified in the literature, might be related to the limitations of the study.
} 
10.1186/s12909-019-1658-z.

[22] Ismail, M. A. A. \& J. Mohammad (2017). Kahoot: A promising tool for formative assessment in medical education. Education in medicine journal 9.2, 19-26. Doi: 19-26. 10.21315/eimj2017.9.2.2.

[23] Jang J., J. J. Y. Park, M. Y. Yi (2015). Gamification of online learning. In C. Conati, N. Heffernan, A. Mitrovic, \& M. Verdejo (eds), Artificial Intelligence in Education. AIED 2015. Lecture Notes in Computer Science (vol. 9112). Springer, Cham. pp. 646-649.

[24] Klimova B. \& J. Kacetl (2018) Computer Game-Based Foreign Language Learning: Its Benefits and Limitations. In S. Cheung, J. Lam, K. Li, O. Au O, W. Ma \& W. Ho (eds.), Technology in Education: Innovative Solutions and Practices, ICTE 2018, Communications in Computer and Information Science 843, 26-34. Singapore: Springer. Doi: 10.1007/978-981-13-0008-0_3.

[25] Lam, S. L. (2014). Use of gamification in vocabulary learning: A case study in Macau. $4^{\text {th }}$ CELL Symposium Proceedings. pp. 90-97.

[26] Lee, J. J., \& J. Hammer (2011). Gamification in education: What, how, why bother? Academic Exchange Quarterly 15, 1-5.

[27] Lekka, A., Ath. Sipsas, \& J. Pagge (2013). Social networks and m-learning: the case of Edmodo. A. Lionarakis (ed.), Proceedings of the $7^{\text {th }}$ International Conference in Open \& Distance Learning. 7 (B): 22-27. Doi: 10.12681/icodl.630.

[28] Licorish, S. A., J. L. George, H. E. Owen \& B. Daniel (2017). "Go Kahoot!" Enriching Classroom Engagement, Motivation and Learning Experience with Games. In W. Chen et al. (eds.), Proceedings of the $25^{\text {th }}$ International Conference on Computers in Education. New Zealand: Asia-Pacific Society for Computers in Education. pp. 755-764.

[29] Liu, X., \& L. C. C Wang (2017). Motivation, learning strategies, and language competency in a technology facilitated Chinese as a second language classroom. Chinese Language Teaching Methodology and Technology 1.2.2.

[30] Long, Y. \& V. Aleven (2014). Gamification of joint student/system control over problem selection in a linear equation tutor. In S. Trau-san-Matu, K. E. Boyer, M. Crosby \& K. Panourgia (eds.), $12^{\text {th }}$ International Conference on Intelligent Tutoring Systems, ITS 2014. Honolulu: Springer International Publishing. pp. 378-387.

[31] Medina, E. G. \& C. P., Hurtado (2017). Kahoot! A digital tool for learning vocabulary in a language classroom. Revista Publicando 12.1, 441-449.

[32] Michos, M. V. (2017). Gamification in foreign language teaching: Do you Kahoot?. Sinteza 2017 - International Scientific Conference on Information Technology and Data Related Research, 511-516. Doi: 10.15308/Sinteza-2017-511-516.

[33] $\mathrm{Mu}, \mathrm{H}$. \& D. Paparas (2015). Incorporating the advantages of clickers and mobile devices to teach Economics to noneconomists. Cogent Economics \& Finance 3, 1-10. Doi: 10.1080/23322039.2015.1099802.

[34] Muhridza, M., N. Hazwani, N. Rosli, A. Sirri \& A. Samad (2018). Using Game-based Technology, KAHOOT! for Classroom Engagement. LSP International Journal 5. Doi: 10.11113/lspi.v5n2.77.

[35] Oomen-Early, J., \& A. D. Early (2015). Teaching in a millennial world: Using new media tools to enhance health promotion pedagogy. Pedagogy in Health Promotion: The Scholarship of Teaching and Learning 1, 95-107.

[36] Owston, R., H. Wideman, N. Ronda \& C. Brown (2009). Computer game development as a literacy activity. Computers \& Education 53, 977-989. Doi: 10.1016/j.compedu.2009.05.015.

[37] Papastergiou, M. (2009). Digital Game-based Learning in high school computer science education: Impact on educational effectiveness and student motivation. Computers \& Education 52, 1-12. Doi: 10.1016/j.compedu.2008.06.004.

[38] Pretorius, C. (2016). Using Kahoot! to enhance the learning experience is Chemistry 176. Blended Learning Case Studies 2016. Centre for learning technologies, Stellenbosch University, 66-68.

[39] Rodríguez-Prieto, J. P. (2014). The use of clickers to assess knowledge in foreign language classes and their failure to increase reading compliance. Revista de Lingüística y Lenguas Aplicadas 9, 88-96. Doi: http://dx.doi.org/10.4995/rlyla.2014.1611.

[40] Rosas, R., M. Nussbaum, P. Cumsille, V. Marianov, M. Correa, P., Flores, V. Grau, F. Lagos, X., López, V. López, P. Rodriguez \& M., Salinas (2003). Beyond Nintendo: Design and assessment of educational video games for $1^{\text {st }}$ and $2^{\text {nd }}$ grade students. Computers \& Education 40, 71-94.

[41] Şad, S. N. \& N. Özer (2019). Using Kahoot! as a gamified formative assessment tool: A case study. International Journal of Academic Research in Education, 5(1), 43-57. DOI: 10.17985/ijare.645584.

[42] Sánchez-Mena, A., J. Martí-Parreño, J. Aldás-Manzano (2016). The role of perceived relevance and attention in teachers intention to use gamification. European Conference on E-Learning. Academic Conferences International Limited. pp. 615-621.

[43] Sindre, G., L. Natvig, M., Jahre (2009). Experimental validation of the learning effect for a pedagogical game on computer fundamentals. IEEE Transactions on Education 52.1, 10-18. Doi: 10.1109/TE.2007.914944.

[44] Spodark, E. (2010). Structuring a language course to respond to millennial generation workplace characteristics. The Language Educator 5.4, 39-42.

[45] Tewthanom K. (2019). The Effect of Kahoot web-based learning on learning skills of pharmacy students: The trend in clinical pharmacokinetics course for 2 generations. Indian Journal of Pharmaceutical Education and Research 53.2, 212-215.

[46] Wang, A. (2015). The wear out effect of a game-based student response system. Computers \& Education 82, 217-227.

[47] Wang, A. I. \& R. Tahir (2020). The effect of using Kahoot! for learning - A literature review. Computers \& Education 149. Doi: 10.1016/j.compedu.2020.103818.

[48] Wichadee, S., \& F. Pattanapichet. (2018). Enhancement of performance and motivation through application of digital games in an English language class. Teaching English with Technology 18.1: 77-92.

[49] Zarzycka-Piskorz, E. (2016). Kahoot it or not? Can games be motivating in learning grammar?. Teaching English with Technology 16.3, 17-36.

Georgios D. Kapsalis is a Professor in Greek Philology at the University of Ioannina (Greece) and former Rector of the University. His main research interests are in language, children's literature and culture. 
Alexandra Galani (Ph.D. in Linguistics, University of York, U.K.) is a Senior Teaching Fellow in Greek as foreign/second language in the Department of Primary Education at the University of Ioannina (Greece). Her main research interests are in morphology and its interfaces as well as foreign language teaching and learning.

Olga Tzafea (Ph. D in Sociology of Education, Master in Linguistics, University of Ioannina, Greece) is a postdoctoral researcher in the Department of Philosophy at the University of Ioannina (Greece) and a teacher of Greek as a foreign/second language in the Center for the Study of the Hellenic Language and Culture at the University of Ioannina (Greece). 